\title{
Treatment of cork boiling wastewater using chemical oxidation and biodegradation
}

\author{
Manuela Dias-Machado ${ }^{\mathrm{a}, \mathrm{c}}$, Luis M. Madeira ${ }^{\mathrm{a}}$, Balbina Nogales ${ }^{\mathrm{b}}$, \\ Olga C. Nunes ${ }^{\mathrm{a}}$, Célia M. Manaia ${ }^{\mathrm{c}, *}$ \\ ${ }^{a}$ LEPAE_Departamento de Engenharia Química, Faculdade de Engenharia, Universidade do Porto, 4200-465 Porto, Portugal \\ b Area de Microbiologia, Universitat de les Illes Balears, Palma de Mallorca, Spain \\ ${ }^{c}$ Escola Superior de Biotecnologia, Universidade Católica Portuguesa, 4200-072 Porto, Portugal
}

Keywords: Polyphenols; Mesophiles; Thermophiles; Tannic acid biodegradation; Fenton oxidation

\begin{abstract}
Three cultures were enriched from cork boiling wastewater using tannic acid as the selective carbon substrate, at $25^{\circ} \mathrm{C}$ and $\mathrm{pH} 7.2$, $25^{\circ} \mathrm{C}$ and $\mathrm{pH} 4.7$ and $50^{\circ} \mathrm{C}$ and $\mathrm{pH}$ 4.7. The enrichment culture obtained at neutral $\mathrm{pH}$ was composed of five culturable isolates, whereas from each acidic enrichment two bacterial strains were isolated. Mesophilic isolates were Gram negative bacteria belonging to the genera Klebsiella, Pseudomonas, Stenotrophomonas and Burkholderia. Thermophilic isolates were members of the genus Bacillus.

Despite the capability of the enrichment cultures to use tannic acid as single carbon and energy source, those cultures were unable to reduce the total polyphenols or the total organic carbon content of cork boiling wastewater. In order to increase the bioavailability of the organic carbon in cork boiling wastewater, biodegradation was preceded by Fenton oxidation. It was demonstrated that the combined process, using small amounts of Fenton reagents and biodegradative inoculum added almost simultaneously to cork boiling wastewater, leads to TOC reductions of more than $90 \%$.
\end{abstract}

\section{Introduction}

Cork production and processing are important sectors of activity in Portugal. After the harvest from the producer tree, Quercus suber L., the cork is stabilised by drying in open air for approximately three months. One of the first stages of industrial preparation of cork consists of its immersion for approximately $1 \mathrm{~h}$ in boiling water. This process improves cork textural and plastic properties, making this material more homogeneous, flat and elastic. The same water may be repeatedly used (20-30 times), reaching temperatures of about $100{ }^{\circ} \mathrm{C}$ during boiling, with variable periods of cooling. Spent cork boiling water is characterized by high chemical oxygen demand (COD), biochemical

\footnotetext{
* Corresponding author. Tel.: +351 22 5580059; fax: +351225090351. E-mail address: cmmanaia@esb.ucp.pt (C.M. Manaia).
}

oxygen demand (BOD) and polyphenols content, in the range of $4.5-5.5 \mathrm{~g}^{-1}, 1.1-1.8 \mathrm{~g}^{-1}$ and $0.6-0.9 \mathrm{~g}^{-1}$, respectively, and by an acidic $\mathrm{pH}$ around 5 (AEP, 2000). Despite the fact that such parameters exceed those legally admitted in residual wastewaters to be released to the environment (Decreto-Lei 236/98, 1998) and that toxicological properties have been described for these effluents (Mendonça et al., 2004), cork boiling wastewaters are frequently discharged without any previous treatment. In fact, cork boiling wastewater treatment imposes some technical and economic constraints, mainly related with the high volumes produced (400 1 ton $^{-1}$ cork) (Mendonça et al., 2004) and the complex nature of the effluent, which requires sophisticated treatment processes.

Several authors have proposed treatment systems for cork processing wastewaters, involving mainly physicalchemical methods. Due to the complexity of the effluent, 
combined methodologies are frequently suggested to treat this kind of wastewater. For example, Fenton oxidation (Guedes et al., 2003), oxidation-coagulation/flocculation (Beltran-Heredia et al., 2004; Peres et al., 2004), flocculation/flotation/ultrafiltration (Minhalma and de Pinho, 2001), and chemical oxidation-photo-oxidation (Acero et al., 2004; Silva et al., 2004). It was previously demonstrated that Fenton oxidation, that consists of the generation of highly reactive hydroxyl radicals $\left({ }^{\circ} \mathrm{OH}\right)$ through catalytic decomposition of hydrogen peroxide, may be used to reduce the COD and BOD levels, increasing the biodegradability of cork boiling wastewaters (Guedes et al., 2003). However, the reagent and catalyst (ferrous ion) added to promote the chemical oxidation are not only expensive but also pollutant agents, and it would be desirable to reduce its use to a minimum.

Biodegradation is viewed as a sustainable process of wastewater treatment, which under appropriate conditions, can promote an efficient reduction of the organic matter content with minimal energy requirements and, therefore, low costs. Major limitations are the bioavailability of the organic matter and the finding of efficient biodegraders. Nevertheless, few reports on cork boiling wastewater biotreatment suggest that this is a promising approach to remediate these wastewaters. Benitez et al. (2003) using activated sludge found chemical oxygen demand (COD) removals between $13 \%$ and $37 \%$, whereas Mendonça et al. (2004) reported COD reductions in the range of $50-60 \%$ promoted by fungi.

Cork boiling wastewater is used at temperatures around $100{ }^{\circ} \mathrm{C}$ and before discharge it is allowed to cool down for a few days. In the present work the possibility to treat the cork boiling wastewater during the cooling period was studied. With this objective, potential polyphenol thermophilic and mesophilic degraders were enriched from cork boiling wastewater, their metabolic versatility was assessed and their capability to remove tannic acid from culture medium was studied. Although these organisms were able to degrade tannic acid, cork boiling wastewater polyphenols were not reduced by their biodegradative activity, suggesting a poor bioavailability of those compounds. Biodegradation was largely improved when bacterial inoculation was accompanied by chemical oxidation.

\section{Materials and methods}

\section{Characterization of cork boiling wastewaters}

Exhausted cork boiling wastewaters (i.e., after being used for 20-30 cycles) were collected from a cork transformation industry in the North of Portugal. Total organic carbon (TOC) was measured by catalytic oxidation/NDIR spectrometry using a TOC-5000 A Shimadzu apparatus. COD and BOD were determined according to Standard Methods (APHA, 1998). Total polyphenols were determined by the Folin-Denis method, calibrated with tannic acid at the same $\mathrm{pH}$ of the sample to analyse (AOAC, 1984). For the enumeration of total heterotrophic bacteria, the samples of boiling wastewater were serially diluted, spread on Plate Count Agar (PCA), and incubated at $25^{\circ} \mathrm{C}$ or $50^{\circ} \mathrm{C}$ for $48 \mathrm{~h}$.

\section{Enrichment cultures}

Samples of cork boiling wastewater were inoculated, in a proportion of $1: 3$ (wastewater:culture medium) in mineral medium B, at pH 7.2 (Barreiros et al., 2003) or at pH 4.7, supplemented with $0.05 \mathrm{~g} \mathrm{l}^{-1}$ of yeast extract, $3.8 \mathrm{mM}$ of $\left(\mathrm{NH}_{4}\right)_{2} \mathrm{SO}_{4}$ and $1 \mathrm{~g}^{-1}$ of tannic acid as carbon and energy source and incubated at $25^{\circ} \mathrm{C}$ or at $50{ }^{\circ} \mathrm{C}$. Medium B at pH 7.2 contained $27 \mathrm{mM}$ phosphate buffer $\left(\mathrm{Na}_{2} \mathrm{HPO}_{4} /\right.$ $\mathrm{KH}_{2} \mathrm{PO}_{4}$ ), while to adjust the $\mathrm{pH}$ to 4.7 only $\mathrm{KH}_{2} \mathrm{PO}_{4}$ was added at a final concentration of $0.8 \mathrm{mM}$. Eight successive transfers at 8-d intervals were made to fresh medium containing $0.2 \mathrm{gl}^{-1}$ tannic acid $(10 \%, \mathrm{v} / \mathrm{v}$ of inoculum). Mesophilic and thermophilic enrichment cultures were designated by the prefix ME or TE, respectively, followed by the $\mathrm{pH}$ of culture medium.

These mineral media were further used to grow the enrichment cultures or the respective isolates, with the same or other carbon sources.

\section{Bacterial isolation, characterization and identification}

In order to identify the culturable members of the enrichment cultures, serial dilutions were spread on Luria Bertani Agar and incubated at $25^{\circ} \mathrm{C}$ or $50^{\circ} \mathrm{C}$. Colonies with distinct morphologies were isolated by sub-culturing on the same medium. A total of nine bacterial isolates were purified and further characterized. The ability of each individual isolate to use phenolic compounds as the only source of carbon and energy was tested in universal flasks containing $4 \mathrm{ml}$ of mineral medium ( $\mathrm{pH} 4.7$ ) supplemented with $0.2 \mathrm{~g}^{-1}$ of the substrate. Additional nutritional versatility tests were based on the Biolog Microplate System according to manufacturer instructions. Isolate TE1 was also tested in a suspension medium with $\mathrm{pH}$ adjusted to 4.7. Each isolate was incubated at the temperature of its isolation.

The identification of the isolates was based mainly on the comparative analysis of the partial $16 \mathrm{~S}$ rDNA sequence (500-600 bp), using the procedure described before (Barreiros et al., 2003). Gram negative isolates were also identified using the API $20 \mathrm{NE}$ or the API 20E (Biomérieux) test systems following the manufacturer instructions.

\section{Biodegradation studies in synthetic medium}

The ability of the enrichment cultures, ME 4.7 and TE 4.7, to degrade tannic acid was determined in cultures grown in mineral medium $\mathrm{pH} 4.7$ with $0.2 \mathrm{~g}^{-1}$ of tannic acid, in Erlenmeyer flasks incubated at $25^{\circ} \mathrm{C}$ (ME 4.7) or $50{ }^{\circ} \mathrm{C}$ (TE 4.7) at $120 \mathrm{rpm}$. Abiotic controls were prepared 
and incubated under the same conditions. Cell growth was monitored by turbidity measurement at $610 \mathrm{~nm}$. Cells dry weight was obtained through a calibration curve of optical density versus cell dry weight. Culture samples were collected along regular intervals, centrifuged at $24000 \mathrm{~g}$, and total polyphenols and TOC contents in the culture supernatant were determined.

\section{Biodegradation assays in cork boiling wastewater}

The capability of enrichment culture ME 4.7 to degrade the polyphenols of cork boiling wastewater was assayed in a well-stirred $500 \mathrm{ml}$ batch reactor, equipped with a cooling jacket, a sintered glass air diffuser, an exhaust, an inlet port for inoculation, and an outlet port for sampling. The reactor was operated with $300 \mathrm{ml}$ of centrifuged $(15000 \mathrm{~g}$, $10 \mathrm{~min}$ ) and filtered (Albet-cellulose nitrate membrane filters, pore size of $0.45 \mu \mathrm{m})$ cork boiling wastewater, at $25^{\circ} \mathrm{C}$ (refrigerated water bath, Huber), magnetic stirring (300 rpm), and $\mathrm{pH}$ monitoring (Inolab). Aerobic conditions were maintained using an air pump, which supplied sterile air through the diffuser at an aeration rate of 0.2 volume of air per volume of reactor per minute. Inoculation was performed with cells washed with sterile saline solution, pre-grown in mineral medium supplemented with tannic acid at $\mathrm{pH} 4.7(10 \%, \mathrm{v} / \mathrm{v}$ of inoculum). A non-inoculated reactor was operated simultaneously under the same conditions. Culture samples were collected at regular time intervals, centrifuged, and total polyphenols and TOC contents in the culture supernatant were determined.

\section{Cork boiling wastewater treatment using Fenton oxidation and biodegradation}

The chemical oxidation was performed in a well-stirred batch reactor of $1500 \mathrm{ml}$. The reactor was operated with $1000 \mathrm{ml}$ of centrifuged and filtered cork boiling wastewater at a controlled temperature of $30^{\circ} \mathrm{C}$ (water bath, Huber), magnetic stirring $(300 \mathrm{rpm})$, and $\mathrm{pH}$ monitoring. The initial $\mathrm{pH}$ of the cork boiling wastewater was adjusted to 3.5 with $0.1 \mathrm{M} \mathrm{H}_{2} \mathrm{SO}_{4}$, followed by the addition of solid iron sulphate (Panreac), and $9.7 \mathrm{M}$ hydrogen peroxide solution (Merck). The $\mathrm{Fe}^{2+}: \mathrm{H}_{2} \mathrm{O}_{2}$ ratio was 1:5 (w/w), with an initial $\mathrm{H}_{2} \mathrm{O}_{2}$ concentration of $5 \mathrm{~g}^{-1}$. Finally, 2-3 drops of anti-foam (Sicolox A 200) was added. The addition of hydrogen peroxide was the initial time for Fenton oxidation. At regular intervals of time (ca. $0,10,20,30 \mathrm{~min}$ ) $100 \mathrm{ml}$ of oxidized wastewater was collected, the $\mathrm{pH}$ was adjusted to 5 with $2 \mathrm{M} \mathrm{NaOH}$, and divided into two Erlenmeyer flasks $(50 \mathrm{ml})$. The oxidized wastewater of one of these flasks was inoculated with cells of enrichment culture ME 4.7 as described above $(10 \%, \mathrm{v} / \mathrm{v}$ of inoculum), while the other constituted the abiotic control. The starting time for biodegradation was the addition of inoculum. The period of time between the addition of hydrogen peroxide and the inoculum was around $6 \mathrm{~min}$. Samples were collected at regular time intervals and TOC content in culture supernatant and total heterotrophic bacteria were determined.

\section{Results and discussion}

\section{Characterization of cork boiling wastewaters}

Three different samples of cork boiling wastewater were analysed for physical-chemical and microbiological parameters (Table 1). Despite the variation on polyphenols and TOC contents of different samples, the wastewater presented low biodegradability with values of the ratio BOD/ COD ranging between 0.15 and 0.21 . Similar values for this kind of wastewater were reported before (Guedes et al., 2003; Silva et al., 2004). There was no evident correlation between the polyphenols and the TOC contents or COD, which may indicate that non-polyphenolic compounds contribute to the values found for such parameters. Total heterotrophic bacteria from different cork boiling wastewater samples, enumerated at $25^{\circ} \mathrm{C}$ and $50^{\circ} \mathrm{C}$, showed that the mesophiles were generally prevalent, both under aerobic or microaerophilic conditions (results not shown), despite the variations observed for distinct samples. A direct competition between mesophiles and thermophiles may be suggested by the fact that higher counts of the first group corresponded to lower counts of the second and vice-versa. Such population variations may be due to the fact that sampling was made at different stages of cooling.

\section{Characterization of enrichment cultures and of the respective isolates}

The enrichment of bacterial cultures from cork boiling wastewater using tannic acid as single carbon and energy source brought additional insights about the diversity and fitness of thermophilic and mesophilic polyphenol consumers in that effluent. Enrichments were conducted at $25^{\circ} \mathrm{C}$ and $50^{\circ} \mathrm{C}$, at $\mathrm{pHs} 7.2$ and 4.7 , in mineral medium supplemented with tannic acid. At $50^{\circ} \mathrm{C}$ and $\mathrm{pH} 7.2$, tannic acid oxidation was evidenced by a fast browning of the culture medium. Furthermore, no bacterial growth was observed after successive transfers of the respective enrichment culture. The remaining cultures could use tannic acid as single

Table 1

Physical-chemical and microbiological characterization of cork boiling wastewater

\begin{tabular}{ll}
\hline Parameter & Range \\
\hline $\mathrm{COD}\left(\mathrm{mg} \mathrm{l}^{-1}\right)$ & $2300-4600$ \\
BOD $\left(\mathrm{mg} \mathrm{l}^{-1}\right)$ & $490-735$ \\
TOC $\left(\mathrm{mg} \mathrm{l}^{-1}\right)$ & $1220-2000$ \\
pH & $4.7-5.7$ \\
Biodegradability (BOD/COD) & $0.15-0.21$ \\
Polyphenols (mg tannic acid $\left.1^{-1}\right)$ & $660-780$ \\
Bacterial enumeration at $\left.25^{\circ} \mathrm{C}(\mathrm{CFU} \mathrm{m})^{-1}\right)$ & $3.8 \times 10^{4}-1.8 \times 10^{7}$ \\
Bacterial enumeration at $\left.50^{\circ} \mathrm{C}(\mathrm{CFU} \mathrm{ml})^{-1}\right)$ & $<1 \times 10^{0}-2.1 \times 10^{4}$ \\
\hline
\end{tabular}


carbon and energy source and the culturable organisms present in those enrichments were further studied. The mesophilic culture enriched at $\mathrm{pH} 7.2$ (ME 7.2) was composed of five distinct Proteobacteria, two belonging to the species Klebsiella pneumoniae $(99.3 \%$ and $99.8 \%$ partial $16 \mathrm{~S}$ rDNA sequence identity with accession number AY552753 and AF453251, respectively), Klebsiella planticola (99.9\% identity with accession number AF129443), Pseudomonas fluorescens $(99.9 \%$ identity with accession number AJ278812) and Stenotrophomonas maltophilia $(99.8 \%$ identity with accession number AJ131117). The acidic mesophilic enrichment (ME 4.7), obtained with a $\mathrm{pH}$ similar to that of cork boiling wastewater ( $\mathrm{pH} 4.7$ ), contained only two culturable bacteria, also belonging to the Proteobacteria. One isolate was identified as Burkholderia tropica (100\% identity with accession number AY561845) and the other as K. pneumoniae (99.6\% identity with accession number AF453251). The comparison of the results obtained at $\mathrm{pH} 7.2$ and 4.7 may indicate that although some bacteria are present in cork boiling wastewater and are able to degrade tannic acid, may be inactive in that effluent due to its acidity. The culturable bacteria isolated from the acidic thermophilic enrichment (TE 4.7) were both endospore forming Gram positive bacteria and were identified as Bacillus licheniformis $(100 \%$ sequence identity with accession number AB055006) and Bacillus sp. (98.3\% sequence identity with Bacillus acidicola, accession number AF547209).

Considering the low $\mathrm{pH}$ of cork boiling wastewater, further studies were conducted only with the acidic enrichment cultures. Due to the complex mixture of polyphenols and other organic compounds that are released from the cork during boiling, it was considered relevant to assess the metabolic versatility of the enrichment cultures and of the respective isolates (Table 2). The mesophilic culture (ME 4.7), composed of Proteobacteria, known for their remarkable metabolic versatility, could use 7 of the 11 phenolic compounds tested as carbon sources, while the thermophilic culture (TE 4.7) only presented growth in caffeic and tannic acids. The respective pure isolates showed a similar trend,

Table 2

Nutritional versatility of cultures ME 4.7 and TE 4.7 and of the respective isolates

\begin{tabular}{lllllll}
\hline Phenolic compounds & \multicolumn{7}{l}{ Bacterial culture } \\
\cline { 2 - 7 } & ME 4.7 & ME1 & ME2 & TE 4.7 & TE1 & TE2 \\
\hline Phenol & w & + & - & - & - & - \\
Tannic acid & + & + & + & + & w & w \\
Salycilic acid & - & - & - & - & - & - \\
Ferulic acid & - & - & - & - & - & - \\
$p$-Coumaric acid & + & - & - & - & - & - \\
Gallic acid & + & w & + & - & - & - \\
Benzoic acid & + & + & - & - & - & - \\
Vanillic acid & - & - & - & - & - & - \\
Caffeic acid & w & + & + & + & w & - \\
Ellagic acid & - & w & w & - & w & - \\
Catechin & w & + & - & - & + & - \\
\hline
\end{tabular}

$\mathrm{W}$, weak. whether tested for assimilation of phenolic compounds or of sugars, organic acids, organic alcohols, aminoacids or nucleotides (results not shown). The most versatile isolate was $K$. pneumoniae ME2 able to use 75 of the 95 carbon substrates tested, followed by B. tropica ME1, able to use 72 different compounds. The thermophile $B$. licheniformis TE2 could use more than half of the substrates tested, while Bacillus sp. TE1 revealed a curious preference for phenolic compounds, as it was unable to use any of the other substrates in neutral or acidic conditions. The inability of each pure mesophilic isolate to grow at expenses of $p$-coumaric acid, while this substrate supported the growth of the respective enrichment culture, may suggest a synergic metabolic association between those organisms, or the presence of unculturable organisms in the mixed culture. The fact that ellagic acid and catechin did not support growth of the thermophilic enrichment culture, although Bacillus sp. TE1 could use those substrates, may be indicative about the type of metabolic association between both isolates or about the proportion of different type of cells in the mixed culture. Eventually, the ability of the thermophilic enrichment culture to degrade phenolic substrates rely upon the capacity of Bacillus sp. TE1 to break down the polyphenols, with a low yield of biomass, with the simultaneous ability of B. licheniformis TE2 to consume the degradation products, with higher growth yields. Also, the production of toxic metabolites in mixed, but not in axenic culture, may be responsible for the absence of growth of enrichment cultures, despite the capacity of individual isolates to use the respective substrate.

\section{Biodegradation of tannic acid in synthetic medium}

Besides the comparative metabolic versatility, it was also important to determine the rate and extent of biodegradation promoted by both enrichment cultures in order to assess the role of microbial populations in cork boiling wastewater treatment. These assays were made using tannic acid as single substrate, which degradation was accompanied by the bacterial growth (Fig. 1a and b). The mesophilic enrichment culture presented a specific growth rate of $0.22 \mathrm{~h}^{-1}$ and degraded the tannic acid to values below the detection limit $\left(20 \mathrm{mg}^{-1}\right)$ after $10 \mathrm{~h}$ of incubation, as indicated by the removal of about $85 \%$ of the initial TOC content (with a biomass yield of about $0.55 \mathrm{mg}$ cells dry weight $\mathrm{mg}^{-1}$ TOC). In contrast, the thermophilic enrichment culture exhibited a lag phase of about $75 \mathrm{~h}$, grew with a much lower specific growth rate $\left(0.06 \mathrm{~h}^{-1}\right)$ and promoted a partial degradation of the substrate, as was indicated by the detection, at the end of the growth, of about $40 \%$ of the initial polyphenols and $50 \%$ of the TOC contents. Also the biomass yield for this culture was much lower, $0.08 \mathrm{mg}$ cells dry weight $\mathrm{mg}^{-1}$ TOC. The incomplete degradation of polyphenols in the medium of the thermophilic enrichment culture may be due to the accumulation of gallic acid, resultant of tannic acid hydrolysis (Baht et al., 1998), which, as was observed in this study, is not used by 


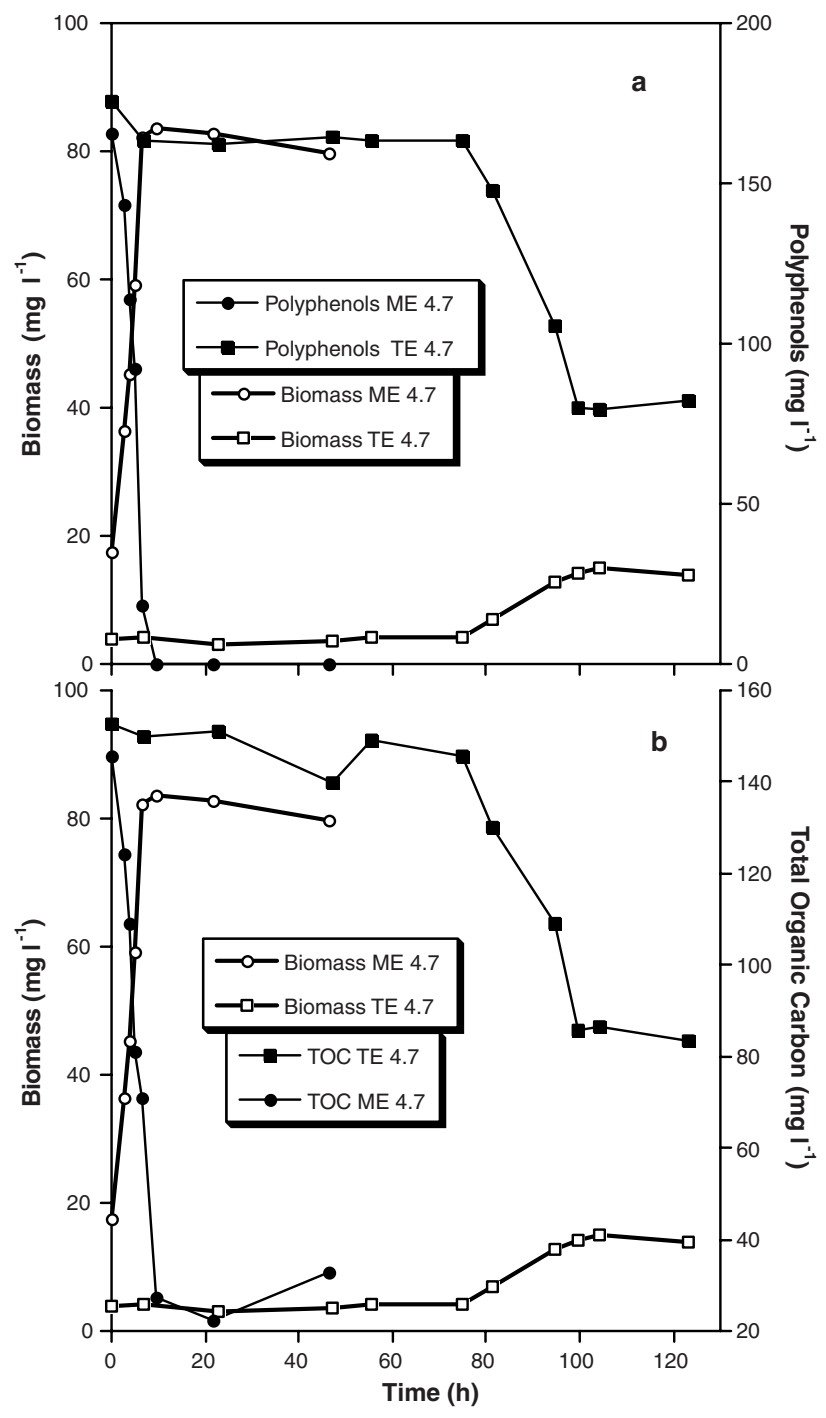

Fig. 1. Growth of enrichment cultures ME 4.7 and TE 4.7 in tannic acid. (a) Growth curves and polyphenols content (mg tannic acid $1^{-1}$ ); (b) growth curves and total organic carbon content $\left(\mathrm{mg}^{-1}\right)$.

those organisms (Table 2). Considering that higher temperatures could have an adverse effect on tannic acid degradation, the thermophilic enrichment culture was assayed at $25^{\circ} \mathrm{C}$. However, the lower temperature of incubation did not improve the efficiency of degradation because a partial and slow degradation was observed (results not shown).

\section{Cork boiling wastewater treatment}

Despite the capacity of enrichment cultures to degrade tannic acid and other polyphenols in synthetic culture medium, these cultures did not improve biodegradation rate and extent, when inoculated in cork boiling wastewater. Indeed, the measured chemical parameters $(\mathrm{pH}$, polyphenols and TOC) were similar along time in inoculated wastewater and in the control (Fig. 2), even when the water was supplemented with inorganic nutrients as nitrogen and phospho-

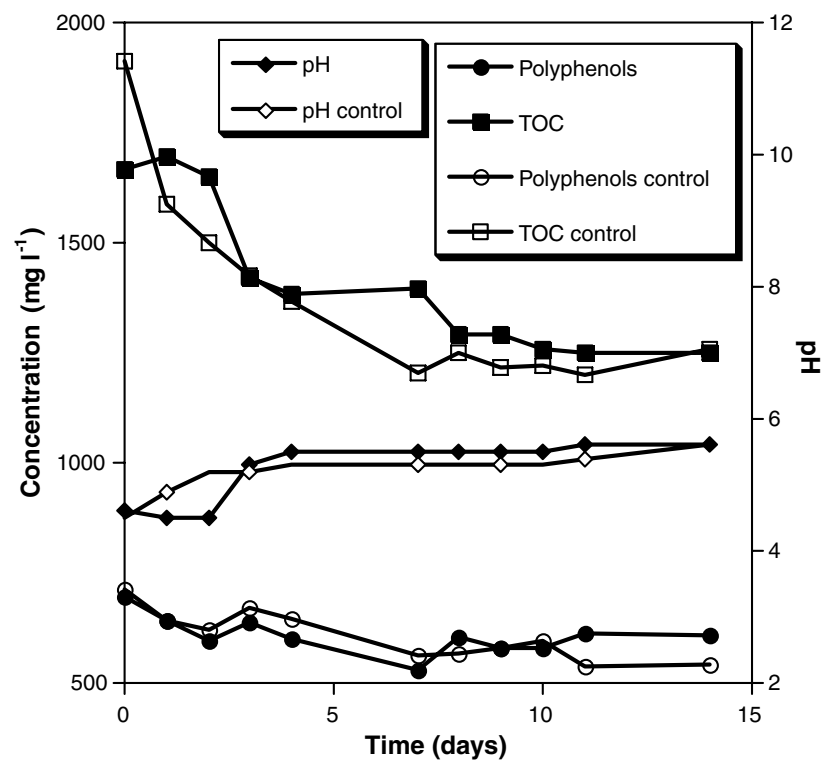

Fig. 2. Polyphenols and total organic carbon contents in cork boiling wastewater inoculated with enrichment culture ME 4.7 and in the respective abiotic control.

rus (results not shown). Similar results were obtained during a resting cells assay, where the inoculum density was 100 times higher (results not shown). Multiple factors may have contributed, independently or together, to such results. For example, the polyphenols in cork boiling wastewater may form chemical complexes, not available for biodegradation; the polyphenols may have an inhibitory effect on the microbial growth and/or catabolic activity; other wastewater components may produce inhibitory effects; some undefined nutritional requirement, absent from the wastewater, may hamper biodegradation.

Considering the hypothesis that polyphenols may form chemical complexes that, besides being unavailable for biodegradation, may produce inhibitory effects on bacteria, a pre-treatment of the effluent seemed an appropriate solution. It was intended to produce a partial chemical oxidation, capable of converting the polyphenols into simpler molecules, increasing their biodegradability (Guedes et al., 2003), using minor amounts of reagents. In this way, the quantity of oxidizing agent (hydrogen peroxide) and catalyst (ferrous ion) were less than a half than those previously recommended for an optimal treatment of similar cork wastewaters (Guedes et al., 2003). Even under these conditions, after 6 min of Fenton oxidation, initial TOC content of about $1400 \mathrm{mg}^{-1}$ decreased to values around $300 \mathrm{mg}^{-1}$, confirming that the first 3-5 min are sufficient to achieve a high degree of chemical degradation (Guedes et al., 2003). The use of a chemical-biological combined methodology, consisting in a Fenton oxidation pre-treatment followed by biodegradation, proved to successfully reduce the TOC of the cork boiling wastewater (Fig. 3a and b). When oxidation/catalytic agents and bacterial inoculum were added almost simultaneously (inoculum added 6 min after hydrogen peroxide), the efficacy of 


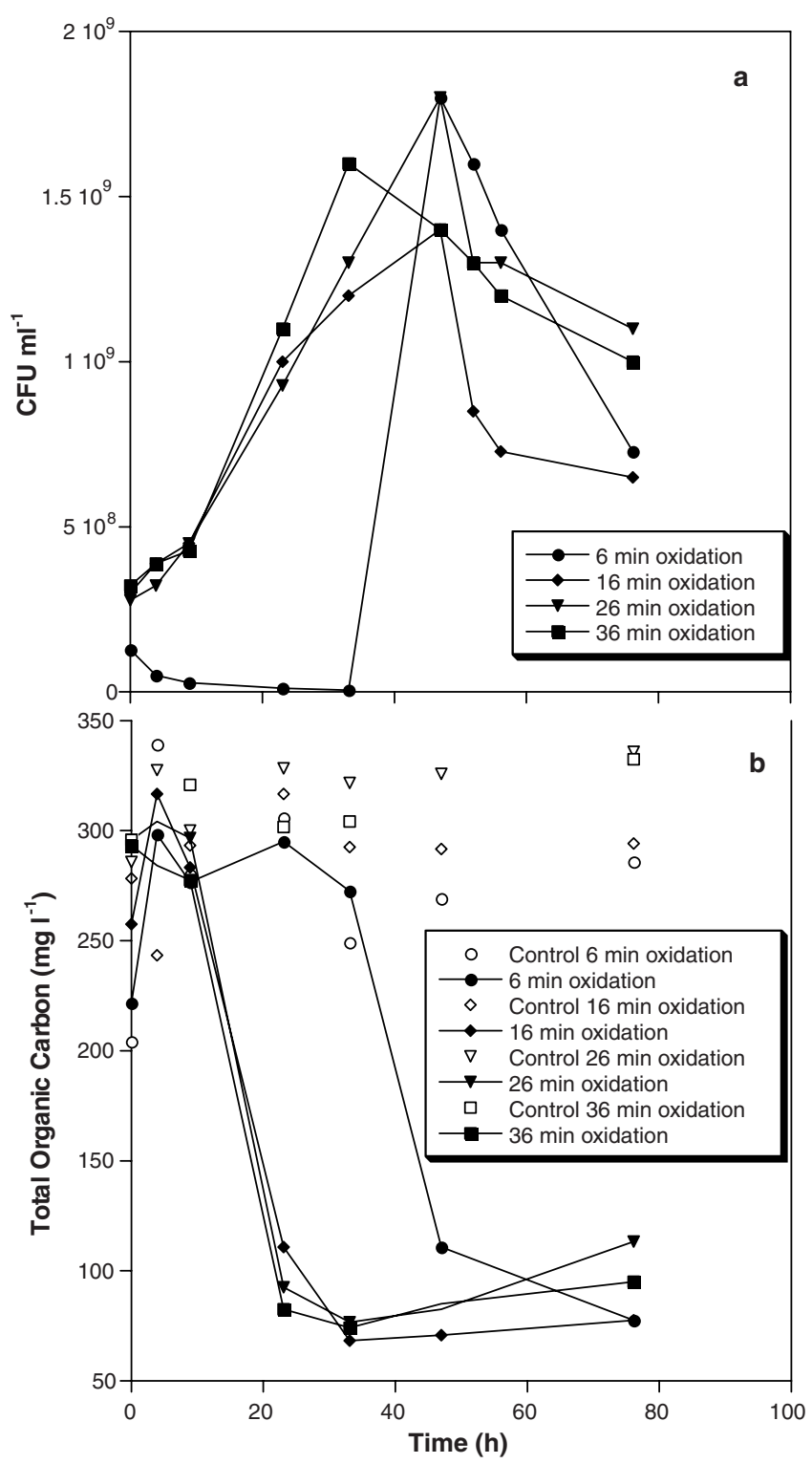

Fig. 3. Growth curves (a) and total organic carbon removal (b) in cork boiling wastewater after Fenton oxidation by enrichment culture ME 4.7. Fenton oxidation proceeded for $0,10,20$ and $30 \mathrm{~min}$ at $30^{\circ} \mathrm{C}, \mathrm{pH} 3.5$ with $\mathrm{Fe}^{2+}: \mathrm{H}_{2} \mathrm{O}_{2}$ 1:5. The oxidized wastewater was adjusted to $\mathrm{pH} 5$ and inoculated after $6,16,26$, and $36 \mathrm{~min}$ of the addition of hydrogen peroxide (initial concentration of $5 \mathrm{~g} \mathrm{l}^{-1}$ ).

TOC removal by mesophilic enrichment culture (ME 4.7) was delayed, probably due to the high amounts of hydrogen peroxide present in the wastewater. Nevertheless, the overall process was not affected and this procedure clearly simplifies the treatment process. In any case, it is worthy to note that when chemical oxidation was let to proceed for 10-20 min before inoculation, TOC reductions up to $92 \%$ were achieved in less than $1 \mathrm{~d}$ (Fig. 3b). Since the temperature is known to have a positive effect on Fenton oxidation for short reaction periods of time (Guedes et al., 2003; Mantzavinos, 2003), the addition of Fenton reagents and the thermophilic inoculum during the cooling phase of the wastewater may contribute to its progressive treatment.
In this respect the low biomass yields observed for the thermophilic enrichment culture may be an advantage.

Due to its chemical composition, mainly its low $\mathrm{pH}$ and high content in complex phenolic compounds, cork boiling wastewater seems inappropriate for direct fast biological treatment. This finding was clearly evidenced by Mendonça et al. (2004) that reported a COD removal of about $60 \%$, after $2 \mathrm{~d}$ of incubation. Other polyphenol rich wastewaters, as for example those derived from olive oil mills, are also referred as not readily biodegradable (Mantzavinos, 2003). However, such difficulties may be overcome if an adequate pre-treatment is applied, as was demonstrated with olive oil mills wastewaters using Fenton and/or ozonization or wet air oxidation (Chakchouk et al., 1994; Andreozzi et al., 1998; Beltran-Heredia et al., 2001).

Even though with Fenton oxidation it is possible to achieve effective COD reductions in cork boiling wastewaters (Guedes et al., 2003), the use of $\mathrm{H}_{2} \mathrm{O}_{2}$ and toxic metals in quantities enough to assure an extensive oxidation of the organic matter may be a disadvantage due to the high cost of the treatment, and because the treated effluent may not be suitable for subsequent discharge or biological treatment (for example in a municipal wastewater treatment plant). For those reasons, it is desirable to reduce those reagents to a minimum as long as degradation can proceed by other processes, assuring the quality of the treated wastewater. The results obtained in the present work show that Fenton oxidation, using small amounts of oxidative/catalyst reagents and a biodegradative inoculum, added almost simultaneously to cork boiling wastewater, leads to TOC reductions of more than $90 \%$, ca. 1.2 times higher than if only chemical oxidation is promoted. The major advantage of the method proposed, besides the use of minor amounts of oxidant, is that the degradation is very fast, being almost complete after $20-30 \mathrm{~h}$ of chemical and biological treatment. This is, in fact, a short period of time when compared with the $2 \mathrm{~d}$ reported by Benitez et al. (2003) using a combined activated sludge-ozonation process, or the $2-4 \mathrm{~d}$ referred by Mendonça et al. (2004) in fungal biotreatment method. Other important innovative aspect of the present study, when compared with previous reports (Benitez et al., 2003; Mantzavinos and Psillakis, 2004), is that the biological agents used were not inhibited by the low $\mathrm{pH}$ of the effluent neither by the chemical oxidation reagents. In future studies it is desirable to optimize the combined process in order to minimize the amounts of $\mathrm{Fe}^{2+}: \mathrm{H}_{2} \mathrm{O}_{2}$, lowering the chemical TOC removal contribution to the minimum necessary to achieve the maximum biological contribution.

\section{Conclusions}

1. Polyphenols in cork boiling wastewater are not readily bioavailable, hampering biodegradation.

2. Chemical oxidation, using minor amounts of oxidative reagents, improves biodegradation, increasing the bio- 
availability of the organic matter in cork boiling wastewater.

3. Culture enrichments, composed of cork boiling wastewater autochthonous microbial biota, could stand the stressful conditions generated by the chemical oxidation reagents.

4. Such combined methodology seems a good alternative for cork boiling wastewater treatment, because it promotes extensive TOC reduction in a short period of time. Additionally, it may be used during the cooling period, allowing the release of a pre-treated effluent.

\section{Acknowledgement}

The authors gratefully acknowledge José Herney Ramirez for technical assistance during Fenton's oxidation assays.

\section{References}

Acero, J.L., Benitez, F.J., Beltran-Heredia, J., Leal, A.I., 2004. Chemical treatment of cork-processing wastewaters for potential reuse. J. Chem. Technol. Biotechnol. 79, 1065-1072.

AEP, 2000. Manual de Boas Práticas Ambientais e Energéticas-Indústria da Cortiça. Associação Empresarial de Portugal, Lisboa, Portugal.

Andreozzi, R., Longo, G., Majone, M., Modesti, M., 1998. Integrated treatment of olive oil mill effluents (OME): study of ozonation coupled with anaerobic digestion. Water Res. 32, 2357-2364.

AOAC, 1984. Official Methods of Analysis, 14th ed. Association of Official Analytical Chemists, Inc., Arlington, Virginia, USA.

APHA, AWWA, WEF, 1998. Standard Methods for the Examination of Water and Wastewater, 20th ed. American Public Health Association, Washington, DC, USA.

Baht, T.K., Singh, B., Sharma, O.P., 1998. Microbial degradation of tannins - a current perspective. Biodegradation 9, 343-357.
Barreiros, L., Nogales, B., Manaia, C.M., Ferreira, A., Pieper, D., Reis, M., Nunes, O.C., 2003. A novel pathway for mineralization on the thiocarbamate herbicide molinate by a defined bacterial mixed culture. Environ. Microbiol. 5, 944-953.

Beltran-Heredia, J., Torregrosa, J., García, J., Domínguez, J.R., Tierno, J.C., 2001. Degradation of olive mill wastewater by the combination of Fenton's reagent and ozonation processes with an aerobic biological treatment. Water Sci. Technol. 44, 103-108.

Beltran-Heredia, J., Domínguez, J.R., López, R., 2004. Treatment of cork process wastewater by a successive chemical-physical method. J. Agric. Food Chem. 52, 4501-4507.

Benitez, F.J., Acero, J.L., Garcia, J., Leal, A.I., 2003. Purification of cork processing wastewaters by ozone, by activated sludge, and by their two sequential applications. Water Res. 37, 4081-4090.

Chakchouk, M., Hamdi, M., Foussard, J.N., Debellefontaine, H., 1994. Complete treatment of olive mill wastewater by a wet air oxidation process coupled with a biological step. Environ. Technol. 15, 323-332.

Decreto-Lei 236/98, 1 August 1998. Anexo XXI, Objectivos Ambientais de Qualidade Mínima para as Águas Superficiais. Diário da República, série I-A, no. 176/98, 3676.

Guedes, A.M.F.M., Madeira, L.M.P., Boaventura, R.A.R., Costa, C.A.V., 2003. Fenton oxidation of cork cooking wastewater-overall kinetic analysis. Water Res. 37, 3061-3069.

Mantzavinos, D., 2003. Removal of cinnamic acid derivatives from aqueous effluents by Fenton and Fenton-like processes as an alternative to direct biological treatment. Water Air Soil Pollut. 3, 211-221.

Mantzavinos, D., Psillakis, E., 2004. Enhancement of biodegradability of industrial wastewaters by chemical oxidation pre-treatment. J. Chem. Technol. Biotechnol. 79, 431-454.

Mendonça, E., Pereira, P., Martins, A., Anselmo, A.M., 2004. Fungal biodegradation and detoxification of cork boiling wastewaters. Eng. Life Sci. 4, 144-149.

Minhalma, M., de Pinho, M.N., 2001. Flocculation/flotation/ultrafiltration integrated process for the treatment of cork processing wastewaters. Environ. Sci. Technol. 35, 4916-4921.

Peres, J.A., Beltran-Heredia, J., Domínguez, J.R., 2004. Integrated Fenton's reagent - coagulation/flocculation process for the treatment of cork processing wastewaters. J. Hazard. Mater. B107, 115-121.

Silva, C.A., Madeira, L.M., Boaventura, R.A., Costa, C.A., 2004. Photooxidation of cork manufacturing wastewater. Chemosphere 55, 19-26. 